Texas A\&M University-San Antonio

Digital Commons @ Texas A\&M University- San Antonio

2015

\title{
Niche Construction and the Evolution of Leadership
}

B. R. Spisak

Michael J. O'Brien

Texas A\&M University-San Antonio, Mike.Obrien@tamusa.edu

N. Nicholson

M. Van Vugt

Follow this and additional works at: https://digitalcommons.tamusa.edu/hist_faculty

Part of the Anthropology Commons

\section{Repository Citation}

Spisak, B. R.; O'Brien, Michael J.; Nicholson, N.; and Van Vugt, M., "Niche Construction and the Evolution of Leadership" (2015). History Faculty Publications. 26.

https://digitalcommons.tamusa.edu/hist_faculty/26

This Article is brought to you for free and open access by the College of Arts and Sciences at Digital Commons @ Texas A\&M University- San Antonio. It has been accepted for inclusion in History Faculty Publications by an authorized administrator of Digital Commons @ Texas A\&M University- San Antonio. For more information, please contact deirdre.mcdonald@tamusa.edu. 


\title{
NICHE CONSTRUCTION AND THE EVOLUTION OF LEADERSHIP
}

\author{
BRIAN R. SPISAK \\ VU University Amsterdam \\ MICHAEL J. O’BRIEN \\ University of Missouri \\ NIGEL NICHOLSON \\ London Business School \\ MARK VAN VUGT \\ VU University Amsterdam and University of Oxford
}

\begin{abstract}
We use the concept of niche construction-the process whereby individuals, through their activities, interactions, and choices, modify their own and each other's environments-as an example of how biological evolution and cultural evolution interacted to form an integrative foundation of modern organizational leadership. Resulting adaptations are formal structures that facilitate coordination of large, postagrarian organizational networks. We provide three propositions explaining how leadership processes evolve over time within and between organizations in order to solve specific coordination problems. We highlight the balancing act between self-interests and group interests in organizations and show how leadership must regulate this tension to maintain organizational fitness. We conclude with predictions about the future evolution of leadership in organizations.
\end{abstract}

Leadership is an important factor contributing to organizational success, yet after centuries of inquiry, leadership theory remains underdeveloped. In response, scholars are generating a growing body of literature on leadership in their attempt to create a more unified theory by highlighting evolutionary processes that are germane to both the biological and cultural dimensions of human behavior (e.g., Nicholson, 2011; Spisak, Nicholson, \& van Vugt, 2011; van Vugt, Hogan, \& Kaiser, 2008). These initiatives fit comfortably with Suddaby, Hardy, and Huy's (2011: 244) point that "it is now time for less consolidation and more provocation" in theory development in the organizational sciences. In this article we combine insights derived from biological science with existing organizational theory to model the evolution of leadership and its impact on organizational change.

We thank former associate editor Neal Ashkanasy and three anonymous reviewers for extremely helpful comments on various drafts. We also thank Richard Arvey, Daniel Balliet, Nancy Blaker, Joep Cornelissen, Allen Grabo, Omar Solinger, and Joshua Tybur for their insightful feedback.
Our contribution focuses on integrated theory building, where multiple elements of the leadership phenomenon, such as individual agents, context, and dynamic interactions, are considered simultaneously (e.g., Avolio, 2007; Lord, Brown, Harvey, \& Hall, 2001). In existing theories scholars have been slow to adopt this approach. One problem is a focus on near-term "how" questions, as opposed to ultimate "why" questions concerning leader-follower motives and interactions. Instead of asking questions regarding "how transformational and transactional leadership dimensions differ" (e.g., Judge \& Piccolo, 2004), we seek to analyze "why different leadership behaviors emerge in the first place"-a question that requires a deeper consideration of leadership as an evolving process. A related issue is the scarcity of interdisciplinary treatments, where new concepts and approaches are brought into the fold of traditional perspectives. This deficit can promote significant miscalculations of organizational management. For example, previous theories focusing primarily on rational agency overlook the noneconomic complexities of the manager-subordi- 
nate interaction (Davis, Schoorman, \& Donaldson, 1997).

Integrated theory building also moves analytic interest well past excessive "gap spotting" (Alvesson \& Sandberg, 2011), which tends to generate suboptimal theory because it underplays the dynamic nature of leadership in organizations (Avolio, 2007; Whetten, 1989). As a consequence of this shortcoming, scholars often frame leadership more in person than in process terms, inviting fundamental attribution errors, such as emphasizing the causal effect of specific leaders on coordination to the exclusion of other situational factors like group size (see Weber, Camerer, Rottenstreich, \& Knez, 2001). Scholars also tend to focus attention more proximately on how leadership operates in a given context, rather than on the complex dynamics linking these individual observations (for an exception see Uhl-Bien, Marion, \& McKelvey, 2007). Thus, a static approach makes it difficult to account for the changing nature of the organizational environment.

Solving these problems requires us to consider how and why varying forms of leadership develop across organizations over time. We adopt the perspective that evolution has endowed humans with attributes and capabilities that govern how we interact with one another in organizations (e.g., Pierce \& White, 1999). In this view cultural evolution is an adaptive extension of biological evolution (Boyd \& Richerson, 1985; Durham, 1991; Laland \& Brown, 2011; Mesoudi, 2011), with both being governed by the same processes: variation, heritability, and selection. Over time, adaptations will encode biologically-such as an instinctive ability and desire to lead and to follow-if selective pressures are strong, consistent, and persistent. Other evolutionary mechonisms will play out culturally over a shorter time span-for example, management adopting hierarchical versus flat leadership structures to coordinate successfully.

This biology-culture connection provides us with a clear set of evolutionary principles to analyze simultaneously proximate, short-term leadership issues as well as longer-range dynamics. This, in turn, takes us to the development of a recursive predictive model: specific leadership traits will be selected for in a particular organizational niche, and the emergent leadership will, over time, modify that niche and codirect organizational change. Leadership is therefore a dual process that emerges from and is the constructor of the organizational environment.

Our model is based on the premise that leadership is a biologically and culturally adaptive process that serves social systems by coordinating and directing effort (von Vugt et al., 2008). The ability to form cohesive groups that effectively coordinate to achieve mutual goals can ultimately enhance fitness (Couzin, Krause, Franks, \& Levin, 2005; Flack, Girvan, de Waal, \& Krakauer, 2006; Horcourt, Ang, Sweetman, Johnstone, \& Manica, 2009). However, organizing the efforts of groups-that is, interdependent individuals who share social identities and have common interests-comes with costs and risks. For example, if "group" is defined at the organizational level, then transaction costs of coordination are high because of the increased likelihood of divergent incentives and routines among individuals and subgroups (Ren, Kiesler, \& Fussell, 2008). An example is the different "pulls" that emerge from competing agendas within some matrix-managed businesses. Firms are continually under pressure to manage such organizational challenges (Gulati \& Singh, 1998). Should a firm, for instance, exploit a wellestablished niche or invest in exploration of a new market for fear of becoming obsolete (March 1991)? The risks associated with on increasing number of these coordination problems can spark damaging conflicts over collective action decisions. It is the presence of such recurrent dilemmas in the environment that selects for adaptive solutions (e.g., Nowak \& Sigmund, 2005).

Thus, leadership can be defined initially as an adaptive process where one or more individuals emerge as a focal point to influence and coordinate behavior for solving social challenges posed by dynamic physical and cultural environments (Hogan, Curphy, \& Hogan, 1994; King, Johnson, \& van Vugt, 2009; Nicholson, 2013; van Vugt, 2006; van Vugt et al., 2008). Indeed, over evolutionary time, environmental pressures facing human groups, such as intergroup conflict, appear to have selected for leadership as one of the principal devices for achieving social coordination (e.g., Pearce, Conger, \& Locke, 2007; van Vugt, 2006; Vaughn, Eerkens, \& Kantner, 2010). In short, the interplay between leadership and followership is a distinctly social process that addresses the critical issues of 
survival and reproduction (Kenrick, Li, \& Butner, 2003; Sober \& Wilson, 1998).

This argument in its general form is neither unique nor revolutionary. However, a particular developmental process of leadership has lacked attention-the evolutionary shift from hunting and gathering to agriculture (Richerson, Boyd, \& Bettinger, 2001; Rowley-Conwy \& Layton, 2011) and the postagrarian organizational transformations that resulted in a multiplicity of leadership structures. Investigating this evolutionary trajectory helps to clarify the role of leadership within the organizational processes of coevolution and niche construction, both as an agent of selection and change and as an object of these processes. In lay terms, leaders make history and history makes leaders (Nicholson, 2013).

\section{NICHE CONSTRUCTION THEORY IN ORGANIZATIONS}

A framework for understanding the coevolutionary nature of leadership and organizations is niche construction theory (NCT), a young branch of evolutionary biology that has become a multidisciplinary movement involving evolutionary biologists, ecologists, psychologists, anthropologists, archeologists, computer scientists, philosophers, and others (Kendal, Tehrani, \& Odling-Smee, 2011; Laland \& O'Brien, 2011). Proponents of NCT have a fundamentally different view of how niches are constructed from that typically found in the social and biological sciences (e.g., Chase \& Leibold, 2003). In contrast to traditional theories of evolution, in which researchers view organisms as molded by environmental pressures, NCT provides a second route to the adaptive fit between organism and environment by emphasizing the capacity of species to modify environmental states. Niche construction theorists propose that, in modifying their own world, organisms frequently modify the environments of other organisms that share those environments. When beavers build dams, for example, they affect considerably more than the probability that genes for dam building will spread. They also modify nutrient cycling and decomposition dynamics, influence the character of water and materials transported downstream, and ultimately influence plant and community composition and diversity (Naiman, Johnston, \& Kelley, 1988). Importantly, the constructed niches also feedback on, and influence, the behaviors of the niche-constructing organisms.

In the human context, niche construction is a process by which we adjust our environment to such a degree that we create our own selection pressures, resulting in distinct adaptations. Constructing niches that are focused on market defense versus prospecting, for example, can select for a diverging set of organizational norms that emphasize the value of congruent behaviors and styles, such as risk aversion at the cost of exploratory innovation. From this perspective, one can use evolutionary mechanisms to model how agents modify the organizational environment and which adaptations are likely to emerge.

The recursive process involves agents responding to fitness-relevant problems posed by their environments and also setting themselves new problems through niche construction. For instance, niche orientations that emphasize the interests of a singular shareholder group versus multiple stakeholder groups can have downstream consequences on the preferential selection of organizational traits (e.g., Donaldson \& Preston, 1995). Specifically, Campbell (2007) has argued that constructing a shareholder-oriented niche can create coordination problems associated with short-term horizons and unsustainable practices. This, in turn, creates new selection pressures favoring perhaps a more sustainable, stakeholder-focused orientation. NCT thus treats evolutionary change as resulting in part from agents codirecting their own evolution (Laland, Odling-Smee, \& Feldman, 2000; Lewontin, 1983; Odling-Smee, Laland, \& Feldman, 2003).

The logic of NCT has long figured in the organizational behavior and management literature. Graen (1975), for example, noted proactive role making as a missing element in role theory. In job design, a similar idea-job crafting-has denoted the tendency of employees to actively shape their jobs (Clegg \& Spencer, 2007; Grant, 2007; Nicholson, 2010). In the careers literature, Van Marnen and Schein (1979) coined the term role innovation to capture a related concept, which later became a central element in the analysis of role transitions and the reshaping of work environments (Nicholson, 1984). Sociologists have also favored the idea of "structuration," capturing the interaction between people and institutional structures (Orlikowski, 1992). Much organizational development can be 
viewed through the NCT lens, such as firms shifting gears in terms of technology, product innovation, staffing criteria, and selection processes.

NCT's strength is in identifying how modifications to a niche, such as a shift in management orientation, lead to the emergence of adaptive traits and strategies favored in the selective environment over time (Laland, Odling-Smee, \& Feldman, 2001; Laland, Odling-Smee, \& Myles, 2010; Odling-Smee, 1988; Rendell, Fogarty, \& Laland, 2011). A primary factor contributing to the progression of human niche construction is our ability to acquire and transmit information quickly through culture (Laland et al., 2000). Relative to genetic inheritance, cultural inheritance can have a more immediate and profound influence on the selective environment because culturally inherited information is not bound by purely genetic pathways for transmission. This means that leadership can rapidly construct a niche through cultural mechanisms.

Scholars have long argued that an essential role of leadership is to shape and oversee the development of organizational culture (e.g., Kaiser, Hogan, \& Craig, 2008; Schein, 1985). For example, formal leadership in an organization may decide to construct a flatter organizational environment. This constructed niche will increase the fitness value and frequency of specific organizational traits, such as democratic normative beliefs and associated behaviors (see Haley \& Sidanius, 2005). Yet, to continue with this example, a flatter structure with democratic norms may not provide the most advantageous outcome in markets that reward problemsolving speed over problem-solving quality, which tend to favor hierarchical networks (see Mihm, Loch, Wilkinson, \& Huberman, 2010). This subsequently reintroduces pressure on formal leadership to enact further niche modifications-in this example, restoring some hierarchical processes-to remain adaptive. Accurately representing this feedback loop between leadership and the organizational niche helps expose the intended and unintended effects of coordinated behavior on organizational development.

Importantly, our model does not assume that all coordinated behavior is caused by leadership. Operational rules, norms, and shared motives-sometimes called "substitutes for leadership" (Howell \& Dorfman, 1981)—are additional sources of coordination. Yet the efficacy of leadership as a solution to coordination challenges derives from its ability to successfully promote the execution of these alternatives. As an example, having a fraction of agents in a group willing to lead the enforcement of prosocial normseven at a personal cost-can significantly enhance the effectiveness of coordination (Bowles \& Gintis, 2004; Gintis, 2000). In this manner some form of coercive leadership advocating affiliative norms can reinforce the observed link between prosocial behavior and organizational commitment (Grant, Dutton, \& Rosso, 2008). Leadership is therefore a central principle of organization because it both initiates and facilitates effective coordination.

\section{COORDINATION AND THE FOUNDATIONS OF MODERN LEADERSHIP}

To appreciate the role of leadership in niche construction, we briefly consider the evolutionary origins of the agricultural revolution. Understanding the emergence of formal leadership and how it has been applied to solve problems in groups potentially increases our foresight about future organizational evolution. The origins of modern civilization were triggered by climatic oscillations during the tail end of the Pleistocene, circa 11,000 years ago, which depleted the resource base and intensified recurrent coordination problems, such as decisions about group movement and intergroup and intragroup conflict (Richerson et al., 2001). These pressures demanded increasingly sophisticated coordination, and existing leadership tendencies were refined and expanded to solve this problem (Flannery, 1968).

Prior to agriculture, hunter-gatherers maintained egalitarion leadership regimes, which have been referred to as "reversed dominance hierorchies" (Boehm, 1993), denoting a powersharing model with flexible leadership and the censoring of what Boehm calls "upstartism." Postagricultural forms differed greatly, some retaining low-power models of leadership, such as the highly collectivist lifestyle of pastoralists (Nicholson, 2005), whereas others-precursors of modern corporate cultures-enabled elaborate resource-based stratification to evolve as a response to the new opportunity to accrue and inherit resources, power, and wealth (e.g., Kirch, 1984; Service, 1975). This facility, in the context of 
fixed settlements, spawned larger and potentially more varied kinds of social networks. Increasing social complexity ushered in a new set of adaptive challenges (O'Brien \& Laland, 2012). Human niches that arose during the agricultural revolution required leadership that not only could manage such essential activities as resource acquisition, distribution, and protection but also could resolve an increasing number of coordination dilemmas, such as managing large-scale conflict within groups and between groups. Table 1 shows the niche construction trajectory from the emergence of large-scale formal leadership in the agricultural revolution to the global leadership of the modern era.

\section{Defining Formal Leadership}

Leadership as an adaptive process for solving these dilemmas comprises active agents who modify culture, initiate niche construction, and alter future environments-what scholars refer to as "ecological inheritance" (Odling-Smee, 1988; Odling-Smee \& Laland, 2011). The key difference between humans and other species, even the closest primates, is the self-conscious intentionality in our niche construction. It is humans' overwhelming sense of agency, purpose, expectation, and planning that forms the cognitive roots of the niche construction we call "culture building" (Nicholson, 2011).

Leadership supports niche construction through directed coordination of individual activities to support the pursuit of joint goals (Hollander, 1992; van Vugt et al., 2008), where "coordination" is defined as "joint interactions that are 'self-policing' because payoffs are highest if everyone does the same thing" (Richerson, Boyd,
\& Henrich, 2003: 358). However, as group size increased across human evolutionary history, genetic relatedness among individuals' decreased, thus enlarging the need for formal leadership to maintain cohesion. The underlying reason for this increased formality is the nepotistic tendency to favor genetically related others (Hamilton, 1964; Neyer \& Lang, 2003). This can hinder large-scale, loosely related coordination as incentives splinter and resource competition between organizational subgroups intensifies (Ren et al., 2008). Thus, formal leadership is a mechanism for maintaining adaptive levels of cohesion between increasingly unrelated group members to enhance the relative fitness of an organization. This makes large-scale formal leadership an essential component to coordinate the behavior of loosely related groups in competitive organizational environments.

\section{Prerequisite Adaptations}

Adapting to complex and dynamic environments in large-scale social groups requires a flexible coordination strategy that is not tuned to any specific environment (Bergstrom, 2002). Leadership, as an evolving process, offers this flexibility across a varied organizational landscape. It is able to serve equally the battle for market share, the cultivation of prosocial human resource management, and the exploration of entrepreneurial opportunities (Zahra \& Pearce, 1990). In modern times, various styles, such as transformational, transactional, or stewardship paradigms, have emerged to enact distinctive coordinating strategies to solve specific group problems (Bass, 1997; Davis et al., 1997; Houghton \& Yoho, 2005).

TABLE 1

Leadership Evolution from the Agricultural Revolution to the Modern Era

\begin{tabular}{llll}
\hline Organizational Properties & Agricultural Revolution & Industrial Revolution & Modern Era \\
\hline Leadership milestones & $\begin{array}{c}\text { Formalized leadership } \\
\text { stabilizes }\end{array}$ & $\begin{array}{c}\text { Industrialized leadership } \\
\text { independent from traditional } \\
\text { ruling class stabilizes }\end{array}$ & $\begin{array}{c}\text { Transnational corporate } \\
\text { leadership expands }\end{array}$ \\
Niche characteristics & - Nested structure & - Emergence of middle class & - Globally diverse executives \\
& - Division of labor & - Emergence of modern unions & - Flatter \\
& - Hierarchical & - Per capita growth & - Decentralized \\
& - Centralized & & - Global middle class growth \\
& - Per capita subsistence & & \\
\hline
\end{tabular}


In addition to flexible large-scale coordination, another component necessary for the development of postagrarian niches is rapid learning, to ensure that group members know and play their part. Humans, and to a limited degree other primates, learn culturally-imitating others and transmitting knowledge within and between generations (Tennie, Call, \& Tomasello, 2009). Because of this ability, we have been referred to as "the ultimate niche constructors" (Odling-Smee et al., 2003: 28).

To execute large-scale niche construction in competitive social environments, learning the rules for coordination is paramount. Formal leadership addresses this concern by increasing the pace of cultural transmission through directed social learning, rather than by relying on individuals to separately adopt their own models, which can decrease relative group cohesion. Specifically, formalized leadership interacts with culture to institutionalize norms and promote uniform enculturation. This is an outcome that is especially desired in modern organizations, which typically comprise unrelated group members who bring their own potentially divisive normative beliefs and practices into the collective. Mentors, educators, and advisers are roles that support the leadership goals of enculturation and niche construction.

\section{THE MODEL: LEADERSHIP AND NICHE CONSTRUCTION}

Evidence for the importance of flexible leadership and cultural learning in human social evolution is compelling. It is both fascinating and helpful to understand what initially allowed us to cross the threshold from informal leadership into formal, less genetically related leadership, given that (1) natural selection focuses primarily on the individual level (Williams, 1966) yet (2) large-scale formalized leadership in loosely related social networks typically involves an asymmetric payoff favoring the leader (i.e., a relative cost to the individual follower; Hammerstein, 2003). A related question concerns why formal leadership was able to stabilize in human culture, rather than humans simply resuming a hunter-gatherer lifestyle when environmental pressures eased, given the potential fitness costs associated with transitioning to large-scale groups (Mummert, Esche, Robinson, \& Armelagos, 2011)? Finally, why did these increasingly formal leadership strategies evolve into the modern structures we currently observe, and what does this imply for future organizational evolution?

It is becoming increasingly clear that embedded in these decision-making processes are the basic mechanisms of evolution, which tend to work on a subconscious level and fully account for apparently nonrational choice (Aktipis \& Kurzbon, 2004; Bentley, O'Brien, \& Brock, 2014). Regardless of whether the pressure is coming from the natural environment or from an organizational niche constructed by leadership, there will exist the same continuing and observable cycle of variation, inheritance, and selection. Incorporating this logic into the study of organizational behavior generates a clear set of propositions for analyzing and predicting change over time.

\section{Leadership Propositions}

To construct our model, we first consider why and when agents sacrifice immediate selfinterest for the sake of the group, even when payoffs gained from the sacrifice asymmetrically favor the leader. Multilevel selection theory deals with the inherent dilemma between self and group when entering loosely related, post-hunter-gatherer niches. Quite simply, if competition between groups is stronger than competition within groups, adaptations benefiting the group will emerge (e.g., Sober \& Wilson, 1998). A version relevant to the study of organizations is referred to as "cultural group selection" (Henrich, 2004). The term followership investment (Spisak et al., 2011) can then be used to capture this self/group trade-off and the opportunity it provides for formal large-scale organizational practices to evolve.

The act of following can be considered an investment of capital, energy, time, or anything else that is a potential cost to an individual in order to accomplish organizational goals. This form of large-scale, asymmetric coordinated investment is possible only if (1) there is a prevailing between-group pressure relative to withingroup pressure, such as market competition, and (2) the perceived return on followership investment is sufficient to increase the fitness of both the group and its individual members. Any form of loosely related, large-scale coordination without these basic rules of multilevel return on 
investment would revert to a more primitive dominance hierarchy where a leader's power was absolute and coordination coerced, generally with minimal benefit to other group members (Wilson, van Vugt, \& O'Gorman, 2008).

The payoffs, however, are perceived, of course. Therefore, individuals may suspend immediate self-interest, despite the absence of $a$ clear long-term payoff. The general need to belong (Baumeister \& Leary, 1995), for example, can encourage followership investment in the group far beyond what appears to be rational. Withholding this fundamental need for sociality would constitute a cost on followers such that going it alone would not be an option. The Machiavellian tactic by some leaders of artificially raising the level of perceived external threat to an organization is another approach that can elicit an apparently irrational level of followership investment. Finally, the presence of actual market competition can also drive this group-level participation. The central idea is that multiple group-level pressures can encourage followership investment, and studying these factors will add to our understanding of organizational involvement and large-scale coordination.

Proposition 1: Followers will be more likely to pursue organizational goals, even at a personal cost to immediate self-interested goals, when withingroup (i.e., individual-level) perceived competition is relatively less than between-group (i.e., group-level) perceived competition.

This adds a worthwhile multilevel dimension to existing motivational theories, such as expectancy theory (Vroom, 1964). Specifically, by including the group-level variable, Proposition 1 predicts that employee motivation can remain high, even when the valence of the expected (individual-level) outcome is negative, provided that the costs and benefits associated with perceived between-group competition are of greater value than the costs and benefits assigned to within-group competition.

Although Proposition 1 provides the rationale for large-scale niche construction, it does little to explain how various leadership processes stabilize (i.e., sustain followership investment and become resistant to change). Research has shown that firms battling for market share in highly competitive markets can sustain a high level of performance with weak "dictatorship" governance, whereas firms not facing intense market competition perform better with good "democratic" governance (Giroud \& Mueller, 2011). Similarly, as Pierce and White (1999, 2006) noted in nonhuman primate and human studies, status-based dominance hierarchies stabilize in ecologies where resources are highly contested (i.e., clustered, predictable, and visible), but egalitarion structures emerge where resources are less contested (i.e., dispersed, unpredictable, and concealed).

We know that followers hold implicit leadership prototypes based on a variety of these evolutionarily consistent group dynamics (e.g., Spisak et al., 2011). Such fitness-relevant coordination problems can include not only the battle for market share but the need for effective intragroup coordination (e.g., through human resource management practices), intergroup coordination (e.g., the management of postmerger integration), and the recurrent dilemma between exploration and exploitation. The main point is that specific coordination problems need to be solved in order to maintain a relative level of organizational fitness. Moreover, as we noted in relation to the adaptive strategies of preagricultural groups, context-specific leadership processes are selected and stabilized in order to address diverging coordination problems. One of the differences with modern organizational niche construction, however, is that coordination challenges intensify when group members are unrelated and diverse. This spurs the evolution and stabilization of more formalized leadership processes with the capacity to facilitate large-scale niche construction.

Specifically, the personal cost associated with followership investment in unrelated groups, combined with a tendency to be self-interested, creates a high level of investment risk (e.g., cheaters may shirk group-level responsibility or leaders may attempt to exploit followers). Common to all coordination problems and subsequent niche construction in loosely related groups is the need to find an adaptive balance between individual-level investment and grouplevel payoff. Low relative payoffs in competitive environments can threaten organizational fitness. This places a premium on the ability to construct a niche that can stabilize adaptive coordination at $\alpha$ higher level than in competitor 
organizations. Understanding how leadership processes stabilize and facilitate fitness-enhancing niche construction is the next step in explaining the evolution of leadership.

The logic of what have been called the three Rs of human cooperation-reciprocation, retribution, and reputation (e.g., Boyd \& Richerson, 1992, 2009; Fehr \& Göchter, 2002; Trivers, 1971)_ can be used to help explain how various forms of formal leadership can occur. Once niche construction begins in an organization, formal leadership must emerge and deploy control mechanisms capable of eliciting the desired norm conformity. A basic requirement for achieving stability is ensuring that the perceived cost of not following a norm is greater than the cost of following it. This we define as "organizational niche equilibrium." It is a situation where the costs of followers switching to available alternatives are too great and the benefits too little, so the niche stabilizes. This can be achieved through various forms of the three Rs.

Take, for instance, the construction of hierarchical versus flat organizational structures to address coordination problems. Management, working to construct a flatter, cooperative niche, needs to maintain reciprocal relationships with multiple subgroups and individuals across the organization. This will likely select for a prosocial leadership process consisting of emotional empathy and other affiliative traits to support multiple streams of reciprocity. The construction of a hierarchical niche, in contrast, creates a rank order of agents where breaches of reciprocity with those lower in rank, such as frontline employees, are likely to occur. Here costly retribution for not following the hierarchical norm may be used to achieve niche stability. Typically, this happens because payoffs asymmetrically favor those at the apex of hierarchies, rather than reciprocity governing exchanges at all levels (Hammerstein, 2003). A constructed niche of this kind will arguably select for a dominance leadership process that encourages vigorous methods of status acquisition and maintenance, such as aggressive behavior and Machiavellian tactics. In this example we see the beginnings of niche construction, where influential stakeholders such as executives and owners modify the environment in an attempt to increase the likelihood of success. The changed context subsequently selects for niche-specific leadership processes to sustain niche equilibrium.
Once established, organizational niches select for relevant and valued characteristics among agents that confer on them reputational and material benefits. For example, a company defending markets compared to one with a prospector orientation (Miles \& Snow, 1978) will accord different value to risk-taking behaviors. Adhering to these niche-specific norms associated with success can consequently add to a positive reputation, increase status, attract cooperation, and ultimately enhance fitness.

Proposition 2: Given group-level investment (Proposition 1), organizational niche construction will stabilize under the following conditions: (a) niche construction selects for niche-specific formal leadership processes that forvor varying degrees of reciprocity versus retribution to sustain followership investment; (b) the selected process is contingent on the level of asymmetric payoff between agents embedded in the niche (e.g., low asymmetry = increased reciprocal strategies); and (c) niche-specific leadership receives higher reputational value (e.g., flat niche + prosocial leadership $=$ high reputation).

We argue that this underlying logic for sustaining followership investment and managing self/ group payoffs applies to all forms of organizational niche construction.

What the stabilization process identified in Proposition 2 does not do, however, is account for the actual modification and evolution of large-scale formalized leadership over time. An additional step is required to explain the wide variety of leadership processes and niche types visible in the organizational landscape. As with all evolutionary mechanisms, stable variation of multiple competing equilibria, such as hierarchical versus flat structures, is required for selection (Boyd \& Richerson, 2009). "Multiple equilibria" means that diverging niche construction gives rise to diverse leadership processes that can become sufficiently stable (i.e., resistant to change) to engage in competitive betweengroup selection. It is at this point where NCT, with its emphasis on downstream behavioral consequences, is perhaps most analytically useful.

Machiavellian-type leaders, for instance, as a result of self-interest, may attempt to sustain 
asymmetric payoffs by exploiting followers' bounded rationality and emotions. Management can signal high levels of explicit concern for corporate social responsibility, in order to appear prosocial, while internal business practices remain nonreciprocating and "easily decoupled," continuing to serve the implicit financial and strategic goals of executives and dominant shareholders (e.g., Weaver, Treviño, \& Cochran, 1999). Indeed, managing followers' emotions is an essential part of the leadership process (Antonakis, Ashkanasy, \& Dasborough, 2009), which can potentially include the use of prosocial "window dressing" as a means to create positive affect. However, we also predict that most forms of asymmetric payoff will have limits and will self-regulate to more symmetrical equilibria because of the cumulative nature of cultural learning. Agents will come to recognize the harmful downstream consequences of their excessive self-interested behaviors and attempt to initiate and stabilize fitness-enhancing alternatives. Gross asymmetries embedded in a niche can quickly become unstable, requiring modifications to the niche for it to remain viable.

Organizations are continually developing these alternative leadership strategies and pitting them against each other in pursuit of market viability. The capacity for innovation, for example, is highly advantageous in many markets. Proposition 1 dictates that a sustained level of between-group competition will elicit group-level investment. This implies that innovation is one organizational phenomenon that creates the need for coordination. Further, Proposition 2 indicates that a particular leadership process will be needed to stabilize the requirements of the situation. Thus, an intense level of market share competition would imply the contingent selection of dominant, hierarchical leadership to quickly establish innovative supremacy. It is important to note that this kind of competition aligns with the primate universal of dominance hierarchy as a mechanism for achieving individual-level success (Nicholson, 2013).

Innovation, however, is an example where a leadership process based on dominance to enact "business warfare" can come to hinder competitive viability. Agents in a hierarchically organized niche may have restricted input and/or may not perceive a reciprocal return on their followership investment (recall that asymmetric payoffs typically favor those at the top) and, therefore, may withhold a percentage of their innovative output. Dhanaraj and Parkhe (2006) use the phrase "shadow of the future" when discussing concerns of reciprocity over time and its impact on innovative performance. Conversely, for subgroups tasked with innovation, we suspect an advantageous alternative is for an organization to construct a niche of cooperation, rather than one of competition, by means of a prosocial, affiliative leadership process. This creates a flatter niche, which increases information flow, perceived reciprocity, and ultimately innovative output. Simply stated, constructing an organizational niche that stabilizes around "how well we work together," rather than "how well we do against other groups," can have a profound evolutionary effect. Proposition 2 holds that in order to construct such a niche, organizations can work to (l) ensure a sense of reciprocity, (2) enhance the reputation of cooperators, and (3) apply retribution to cheaters.

What priority is assigned to various organizational goals, such as innovation, postmerger integration, and various organizational hurdles, depends on the importance of the challenge. Additionally, how the organization coordinates behavior in pursuit of these goals depends on the type of niche construction established by key stakeholders (e.g., decisions about hierarchy, division of labor, centralization, and other pillars of organizational design; Rivkin \& Siggelkow, 2003). Continuing with the innovation example, assigning priority to innovation may induce management to construct flat structures with a multidisciplinary division of labor in order to stimulate and coordinate the processes of invention. Leadership emerging from this orientation consequently sustains the niche through application of the three Rs, which advances niche construction in the intended direction of flat and reciprocal. Again, the leadership process is both a driver and product of organizational evolution, and cultural learning rapidly transmits and stabilizes subsequent adaptations.

Crossing the threshold into large-scale groups was human evolution's "big bang." The ability to niche construct on a large and complex scale, through the initiation and facilitation of leadership, afforded humans the opportunity to create more than enough stable variation to fuel continuous organizational evolution. How 
an organization chooses to prioritize and coordinate its actions relative to those of its competitors forms the foundation of organizational niche construction.

Proposition 3: Given group-level investment (Proposition 1) and the mechanisms for constructing a stable niche (Proposition 2), large-scale formalized leadership dynamics will evolve under the following conditions: (a) organizations face multiple coordination problems with varying payoffs; (b) strategic alternatives are prioritized to maintain relative fitness between organizations (e.g., high priority assigned to innovation); (c) niche construction trajectories (e.g., hierarchal versus flat orientations) set by influential stakeholders select for multiple equilibria of niche-specific leadership processes (e.g., dominance versus prosocial), which stabilize between organizations (voriation); (d) fitness-enhancing leadership processes increase in frequency by means of cultural learning (inheritance), and processes with higher relative paryoffs between organizations persist (selection); (e) group success decreases group-level competition and increases individual-level competition; and (f) individual-level competition decreases group-level fitness, which creates a feedback loop requiring further niche construction to maintain a relative level of organizational success (see Figure 1).

One testable prediction that can be derived from Proposition 3 is that as group-level competition increases globally-the rise of Asian firms, for example-group-level investment within competing firms will increase to sustain relative fitness. This means that asymmetric payoffs within an organization will decrease and prosocial leadership processes will increase in frequency to secure increased levels of reciprocity and group-level investment across the organization. This prosocial switch will have a cascading effect on other processes, such as leadership emergence. Research has shown, for instance, that followers tend to favor female leaders in a prosocial context (e.g., van Vugt \& Spisak, 2008). Likewise, as we previously discussed, the increase in reciprocity should also have a positive impact on the quality of innova-
FIGURE 1

\section{An Evolutionary Cycle of Organizational Leadership Resulting from Coordinated Human Niche Construction}

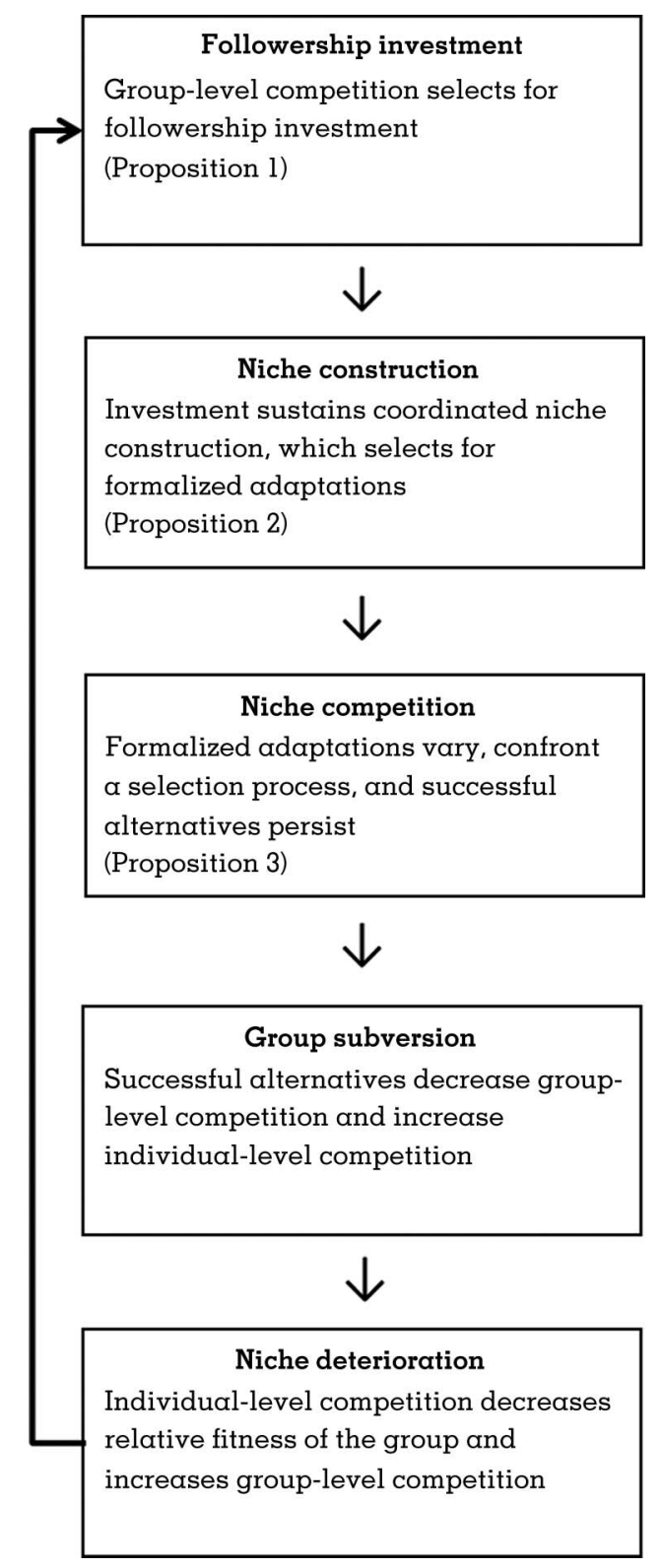

tive output. Consequently, groups that successfully work together by enacting relatively more adaptive leadership processes will increase the overall fitness of each member (Sober \& Wilson, 1998; Williams, 1966). Those groups, and ultimately individuals, maintaining larger and more integrated networks are likely to have greater intragroup stability, access to scarce resources, and success during intergroup compe- 
tition. They are also more likely to pass on their acquired knowledge through cultural learning. Hence, large-scale formal leadership is fundamentally a mechanism for expanding these adaptive organizational networks.

\section{Implications for Leadership and Organizational Evolution}

As groups become larger and more complex, formalized leadership maximizes the benefit of sociality by regulating tensions between individual- and group-level interests to ensure a healthy level of group investment. This fitnessenhancing advantage of formal leadership structures then spreads throughout large-scale societies. The reason for such ubiquity is that formal leadership is versatile enough to provide the global institutional foundation required to cooperate on a large scale (e.g., maintaining relatively equitable payoffs), as well as the local organization necessary to prioritize and manage specific tasks. Leadership both defines organizational strategies and initiates collective action to achieve objectives.

\section{The Coevolution of Formal Leadership and Cultural Niches}

What we observe in the postagrarian era, not seen before, is a compounding effect of adaptation passing through larger, more complex social networks, which encourages the pathways to increase in complexity as further niche construction occurs. For example, as a result of niche construction, the level of sustainable group density rises and formal leadership roles emerge with greater refinement. These are the downstream consequences. A larger population, as a result of niche construction, creates increasingly complex networks, and subsequent social stratification imposes structural constraints (i.e., formalized hierarchy)—further downstream consequences. We suggest these factors lead to exceptionally influential leadership opportunities, such as many CEO positions. These leadership hubs have greater access and control over resources and, thus, become focal points of networks.

We argue that formalized leadership in its many forms can exercise an unprecedented degree of control over network behavior and niche construction. In essence, formal leadership pro- vides a degree of "direction" to organizational evolution. As social complexity increases, the possible directions to drive niche construction diversify (Proposition 3). Leadership's construction of relatively more successful niches will typically increase a group's status, causing others to adopt its fitness-enhancing cultural adaptations to remain competitive (e.g., Mesoudi, 2008). This involves cultural knowledge sweeping across social networks containing multiple organizations. In these networks various alternatives undergo selection and adaptive information is transmitted. The communications supporting this diffusion can range from simple proximity, such as familial transmission in highly related groups (e.g., Henrich \& Henrich, 2010), to complex interorganizational transmission via interlocking directorates (e.g., Carpenter \& Westphal, 2001).

Research on firms, however, indicates that imitation is not costless (Lieberman \& Asaba, 2006). A formalized leadership structure creates more centralized power, which potentially influences the trajectory of cultural evolution toward institutionalized norms that reinforce those in centralized positions-dominant shareholders, for instance. This presumably results from the tendency to enhance individual-level success (Williams, 1966). Thus, niche construction activities will likely include architecture designed to asymmetrically channel benefits toward the top. If centralized leadership in other groups begins to adopt this self-interested strategy, then the individual- and group-level balance necessary to maintain formal structures is jeopardized. The imbalance is likely to grow until the group, including the leaders benefiting from such asymmetry, fails. Proposition 3 states that an important deterrent against such failure is maintained by between-group competition (Figure 1). Thus, laws preventing monopolies and other competition-reducing practices potentially ensure equitable group investment and longterm organizational fitness, even for the monopolizing organization.

In the context of the leadership literature, this balancing act between individual and group interests is the basis of leader-member exchange and path-goal theories (e.g., Dienesch \& Liden, 1986; House, 1971), which seek to explain why certain maladaptive leadership traits do not necessarily drive groups to extinction. In fact, they rarely do (Laland \& Brown, 2006). Any dis- 
parity in individual within-group fitness will have a threshold based on perceived and actual payoffs in competitive between-group environments so that overall group fitness cannot drop below levels of other groups without negative consequences for all individuals within the group (Proposition 1). Formal leadership can evolve to create stable hierarchical structures to benefit group members unequally (Proposition 2), although this will be curtailed by adaptations for group-level investments that enable organizations to meet the challenge of betweengroup competition (Proposition 3). For example, training and development programs are grouplevel initiatives that restrict the ability of leaders to pursue cronyism by increasing expert power across the organization through knowledge sharing.

The human ability to learn at a ropid pace, together with a stable and cumulative transgenerational culture (Tennie et al., 2009), allows cultural knowledge to spread through social networks. This modifies the cultural niche and generates $a$ countervailing feedback pressure on formal leadership. Thus, we observe a coevolution between leadership and niches in the pursuit of organizational success. In this cultural space, contrasting niche construction activities battle for supremacy. By adjusting perceptions of costs and benefits, competing leadership initiatives can work to secure investments and stabilize adaptations. Some groups might construct a hierarchical niche to encourage innovation, whereas others might stabilize a flatter structure. The goal is to focus investment and to secure fitness in a competitive environment. This drives the niche-constructing activities observed across organizations.

\section{Limitations and Future Research}

Although it is clear that formal leadership can have a significant impact on success, we continue the search to improve our model. A number of limitations and boundary conditions exist. For instance, as an introduction to niche construction and formal leadership emergence, the current model would become too complex to cover all aspects of the leadership process in one stroke. Future versions will need to account for emotions, personality, and other individual differences, as well as specific cultural and ecological variations. Such advances will increase the accuracy of modeling the coevolutionary relationship between leadership and organizational niches.

To encourage continued model development, our work has a number of implications for the direction of research in leadership and organizational behavior. We have offered a framework that connects both the social and biological perspectives on leadership by means of niche construction. It is valuable to consider a broader understanding of human behavior, given the intimate connection between biology and culture in our species. The biological sciences, for instance, provide insights into fundamental human tendencies, which help to clarify what adaptations are likely to occur under different organizational pressures, whereas the social sciences provide information about specific organizational environments. The main point is that incorporating niche construction into the organizational and management sciences unlocks a wealth of multidisciplinary research to yield future insights.

Future work could also investigate other modifications of formal leadership resulting from the multilevel tension embedded within postagrarian niches. It would be beneficial to understand how pressures in the environment, such as the rise of market competition in developing economies, influence the evolution of institutions and their leadership manifestations. We suspect that management practices will need to become significantly less hierarchical, dominant, and homogeneous to remain successful in an increasingly connected, informed, diverse, and alternative-rich environment (e.g., Bentley et al., 2014). Digital communities provide employees with an ability to maintain highly networked, decentralized social links, enabling rapid information sharing and the exploration of opportunities on a global scale. Likewise, the shift from nonrenewable to renewable energy sources, as a result of an overly exploited niche, is moving societies toward exploratory goals, which implies a need for flatter, innovationfriendly leadership structures.

\section{CONCLUSIONS}

In preagricultural society, dromatic shifts in the Pleistocene natural environment selected biologically for cultural learning and leadership (Richerson \& Boyd, 2000). We propose that in- 
creased stable transgenerational knowledge intensified social competition among groups and activated group-level pressures that selected culturally for the formalization of leadership. This, in turn, facilitated the emergence of largescale organization. Niche construction in this complex network created countless varieties of organizational behaviors and leadership adaptations, which were, and continue to be, pitted against one another in a seemingly endless struggle. Cultural adaptations for formal leadership then modified niches, adjusting cultural practices to secure an adaptive balance between individual- and group-level benefits.

History has witnessed huge variation in leadership forms, including despotic rule, transformational agents, industry bureaucrats, and democratic representatives. We feel violated when despots place too much emphasis on individual-level advantage, and we experience a sense of security when our representatives work to protect us from external threats and internal power abuses. There is no doubt that considerable variation in formal leadership will persist in the extreme diversity of modern institutional niches. Under what circumstances is an unregulated for-profit model sustainable? Can a highly centralized system compete with flatter structures in the face of globalized competition? How will cultural differences be leavened by the shrinking geospatial effect of cyberconnectivity? Ultimately, it will be the quality of leadership and the willingness and ability of followers to execute niche construction strategies that will dictate the success and failure of future organizational forms.

\section{REFERENCES}

Aktipis, C. A., \& Kurzban, R. 2004. Is homo economicus extinct?: Vernon Smith, Daniel Kahneman and the evolutionary perspective. In R. Koppl (Ed.), Advances in Austrian economics: 135-153. Amsterdam: Elsevier.

Alvesson, M., \& Sandberg, J. 2011. Generating research questions through problematization. Academy of Management Review, 36: 247-271.

Antonakis, J., Ashkanasy, N. M., \& Dasborough, M. T. 2009. Does leadership need emotional intelligence? Leadership Quarterly, 20: 247-261.

Avolio, B. J. 2007. Promoting more integrative strategies for leadership theory-building. American Psychologist, 62: 25-33.

Bass, B. M. 1997. Does the transactional-ransformational par- adigm transcend organizational and national boundaries? American Psychologist, 52: 130-139.

Baumeister, R. F., \& Leary, M. R. 1995. The need to belong: Desire for interpersonal attachments as a fundamental human motivation. Psychological Bulletin, 117: 497-529.

Bentley, R. A., O'Brien, M. J., \& Brock, W. A. 2014. Mapping collective behavior in the big-data era. Behavioral and Brain Sciences, 37: 63-119.

Bergstrom, T. C. 2002. Evolution of social behavior: Individual and group selection. Journal of Economic Perspectives, 16(4): 67-88.

Boehm, C. 1993. Egalitarian behavior and reverse dominance hierarchy. Current Anthropology, 34: 227-254.

Bowles, S., \& Gintis, H. 2004. The evolution of strong reciprocity: Cooperation in heterogeneous populations. Theoretical Population Biology, 65: 17-28.

Boyd, R., \& Richerson, P. J. 1985. Culture and the evolutionary process. Chicago: University of Chicago Press.

Boyd, R., \& Richerson, P. J. 1992. Punishment allows the evolution of cooperation (or of anything else) in sizable groups. Ethology and Sociobiology, 13: 171-195.

Boyd, R., \& Richerson, P. J. 2009. Culture and the evolution of human cooperation. Philosophical Transactions of the Royal Society B: Biological Sciences, 364: 3281-3288.

Campbell, J. L. 2007. Why would corporations behave in socially responsible ways? An institutional theory of corporate social responsibility. Academy of Management Review, 32: 946-967.

Carpenter, M. A., \& Westphal, J. D. 2001. The strategic context of external network ties: Examining the impact of director appointments on board involvement in strategic decision making. Academy of Management Journal, 44: $639-660$.

Chase, J. M., \& Leibold, M. A. 2003. Ecological niches: Linking classical and contemporary approaches. Chicago: University of Chicago Press.

Clegg, C., \& Spencer, C. 2007. A circular and dynamic model of the process of job design. Journal of Organizational and Occupational Psychology, 80: 321-339.

Couzin, I. D., Krause, J., Franks, N. R., \& Levin, S. A. 2005. Effective leadership and decision-making in animal groups on the move. Nature, 434: 513-516.

Davis, J. H., Schoorman, F. D., \& Donaldson, L. 1997. Toward a stewardship theory of management. Academy of Management Review, 22: 20-47.

Dhanaraj, C., \& Parkhe, A. 2006. Orchestrating innovation networks. Academy of Management Review, 31: 659-669.

Dienesch, R. M., \& Liden, R. C. 1986. Leader-member exchange model of leadership: A critique and further development. Academy of Management Review, 11: 618634.

Donaldson, T., \& Preston, L. E. 1995. The stakeholder theory of the corporation: Concepts, evidence, and implications. Academy of Management Review, 20: 65-91.

Durham, W. H. 1991. Coevolution: Genes, culture, and human diversity. Stanford, CA: Stanford University Press. 
Fehr, E., \& Göchter, S. 2002. Altruistic punishment in humans. Nature, 415: 137-140.

Flack, J. C., Girvan, M., de Waal, F. B., \& Krakauer, D. C. 2006. Policing stabilizes construction of social niches in primates. Nature, 439: 426-429.

Flannery, K. V. 1968. Archaeological systems theory and early Mesoamerica. In B. J. Meggers (Ed.), Anthropological archaeology in the Americas: 67-87. Washington, DC: Anthropological Society of Washington.

Gintis, H. 2000. Strong reciprocity and human sociality. Journal of Theoretical Biology, 206: 169-179.

Giroud, X., \& Mueller, H. M. 2011. Corporate governance, product market competition, and equity prices. Journal of Finance, 66: 563-600.

Graen, G. 1975. Role-making processes within complex organizations. In M. D. Dunnette (Ed.), Handbook of industrial and organizational psychology: 1202-1245. Chicago: Rand McNally.

Grant, A. M. 2007. Relational job design and the motivation to make a prosocial difference. Academy of Management Review, 32: 393-417.

Grant, A. M., Dutton, J. E., \& Rosso, B. D. 2008. Giving commitment: Employee support programs and the prosocial sensemaking process. Academy of Management Journal, 51: 898-918.

Gulati, R., \& Singh, H. 1998. The architecture of cooperation: Managing coordination costs and appropriation concerns in strategic alliances. Administrative Science Quarterly, 43: 781-814.

Haley, H., \& Sidanius, J. 2005. Person-organization congruence and the maintenance of group-based social hierarchy: A social dominance perspective. Group Processes \& Intergroup Relations, 8: 187-203.

Hamilton, W. D. 1964. The genetical evolution of social behaviour. I. Journal of Theoretical Biology, 7: 1-16.

Hammerstein, P. (Ed.). 2003. Genetic and cultural evolution of cooperation. Cambridge, MA: MIT Press.

Harcourt, J. L., Ang, T. Z., Sweetman, G., Johnstone, R. A., \& Manica, A. 2009. Social feedback and the emergence of leaders and followers. Current Biology, 19: 248-252.

Henrich, J. 2004. Cultural group selection, coevolutionary processes and large-scale cooperation. Journal of Economic Behavior \& Organization, 53: 3-35.

Henrich, J., \& Henrich, N. 2010. The evolution of cultural adaptations: Fijian food taboos protect against dangerous marine toxins. Proceedings of the Royal Society B: Biological Sciences, 277: 3715-3724.

Hogan, R., Curphy, G. J., \& Hogan, J. 1994. What we know about leadership. American Psychologist, 49: 493-504.

Hollander, E. P. 1992. The essential interdependence of leadership and followership. Current Directions in Psychological Science, 1: 71-75.

Houghton, J. D., \& Yoho, S. K. 2005. Toward a contingency model of leadership and psychological empowerment: When should self-leadership be encouraged? Journal of Leadership and Organizational Studies, 11(4): 65-83.
House, R. J. 1971. A path goal theory of leader effectiveness. Administrative Science Quarterly, 16: 321-339.

Howell, J. P., \& Dorfman, P. W. 1981. Substitutes for leadership: Test of a construct. Academy of Management Journal, 24: 714-728.

Judge, T. A., \& Piccolo, R. F. 2004. Transformational and transactional leadership: A meta-analytic test of their relative validity. Journal of Applied Psychology, 89: 755768.

Kaiser, R. B., Hogan, R., \& Craig, S. B. 2008. Leadership and the fate of organizations. American Psychologist, 63: $96-$ 110.

Kendal, J., Tehrani, J. J., \& Odling-Smee, J. 2011. Human niche construction in interdisciplinary focus. Philosophical Transactions of the Royal Society B: Biological Sciences, 366: 785-792.

Kenrick, D. T., Li, N. P., \& Butner, J. 2003. Dynamical evolutionary psychology: Individual decision rules and emergent social norms. Psychological Review, 110: 3-28.

King, A. J., Johnson, D. D., \& van Vugt, M. 2009. The origins and evolution of leadership. Current Biology, 19: R911R916.

Kirch, P. V. 1984. The evolution of the Polynesian chiefdoms. Cambridge: Cambridge University Press.

Laland, K. N., \& Brown, G. R. 2006. Niche construction, human behavior, and the adaptive-lag hypothesis. Evolutionary Anthropology, 15(3): 95-104.

Laland, K. N., \& Brown, G. R. 2011. Sense and nonsense: Evolutionary perspectives on human behaviour (2nd ed.). Oxford: Oxford University Press.

Laland, K. N., \& O'Brien, M. J. 2011. Cultural niche construction: An introduction. Biological Theory, 6: 191-202.

Laland, K. N., Odling-Smee, F. J., \& Feldman, M. W. 2000. Niche construction, biological evolution, and cultural change. Behavioral and Brain Sciences, 23: 131-175.

Laland, K. N., Odling-Smee, F. J., \& Feldman, M. W. 2001. Cultural niche construction and human evolution. Journal of Evolutionary Biology, 14: 22-33.

Laland, K. N., Odling-Smee, J., \& Myles, S. 2010. How culture shaped the human genome: Bringing genetics and the human sciences together. Nature Reviews Genetics, 11: 137-148.

Lewontin, R. C. 1983. Gene, organism, and environment. In D. S. Bendall (Ed.), Evolution from molecules to men: 273-285. Cambridge: Cambridge University Press.

Lieberman, M. B., \& Assaba, S. 2006. Why do firms imitate each other? Academy of Management Review, 31: 366385.

Lord, R. G., Brown, D. J., Harvey, J. L., \& Hall, R. J. 2001. Contextual constraints on prototype generation and their multilevel consequences for leadership perceptions. Leadership Quarterly, 12: 311-338.

March, J. G. 1991. Exploration and exploitation in organizational learning. Organization Science, 2: 71-87.

Mesoudi, A. 2008. An experimental simulation of the "copysuccessful-individuals" cultural learning strategy: 
Adaptive landscapes, producer-scrounger dynamics and informational access costs. Evolution and Human Behavior, 29: 350-363.

Mesoudi, A. 2011. Cultural evolution: How Darwinian theory can explain human culture \& synthesize the social sciences. Chicago: University of Chicago Press.

Mihm, J., Loch, C. H., Wilkinson, D., \& Huberman, B. A. 2010. Hierarchical structure and search in complex organizations. Management Science, 56: 831-848.

Miles, R. E., \& Snow, C. C. 1978. Organizational strategy, structure and process. New York: McGraw-Hill.

Mummert, A., Esche, E., Robinson, J., \& Armelagos, G. J. 2011. Stature and robusticity during the agricultural transition: Evidence from the bioarchaeological record. Economics \& Human Biology, 9: 284-301.

Naiman, R. J., Johnston, C. A., \& Kelley, J. C. 1988. Alterations of North American streams by beaver. Bioscience, 38: 753-762.

Neyer, F. J., \& Lang, F. R. 2003. Blood is thicker than water: Kinship orientation across adulthood. Journal of Personality and Social Psychology, 84: 310-321.

Nicholson, N. 1984. A theory of work role transitions. Administrative Science Quarterly, 29: 172-191.

Nicholson, N. 2005. Meeting the Maasai: Messages for management. Journal of Management Inquiry, 14: 255-267.

Nicholson, N. 2010. The design of work: An evolutionary perspective. Journal of Organizational Behavior, 31: 422431.

Nicholson, N. 201l. The evolved self, coevolutionary processes and the self-regulation of leadership. Biological Theory, 6: 12-44.

Nicholson, N. 2013. The "I" of leadership: Strategies for seeing, being and doing. Chichester, UK: Jossey-Bass.

Nowak, M. A., \& Sigmund, K. 2005. Evolution of indirect reciprocity. Nature, 437: 1291-1298.

O'Brien, M. J., \& Laland, K. N. 2012. Genes, culture and agriculture: An example of human niche construction. Current Anthropology, 53: 434-470.

Odling-Smee, F. J. 1988. Niche constructing phenotypes. In H. C. Plotkin (Ed.), The role of behavior in evolution: 73-132. Cambridge, MA: MIT Press.

Odling-Smee, F. J., \& Laland, K. N. 2011. Ecological inheritance and cultural inheritance: What are they and how do they differ? Biological Theory, 6: 220-230.

Odling-Smee, F. J., Laland, K. N., \& Feldman, M. W. 2003. Niche construction: The neglected process in evolution. Monographs in Population Biology: 37. Princeton, NJ: Princeton University Press.

Orlikowski, W. J. 1992. The duality of technology: Rethinking the concept of technology in organizations. Organization Science, 3: 398-427.

Pearce, C. L., Conger, J. A., \& Locke, E. A. 2007. Shared leadership theory. Leadership Quarterly, 18: 281-288.

Pierce, B. D., \& White, R. 1999. The evolution of social structure: Why biology matters. Academy of Management Review, 24: 843-853.
Pierce, B. D., \& White, R. 2006. Resource context contestability and emergent social structure: An empirical investigation of an evolutionary theory. Journal of Organizational Behavior, 27: 221-240.

Ren, Y., Kiesler, S., \& Fussell, S. R. 2008. Multiple group coordination in complex and dynamic task environments: Interruptions, coping mechanisms, and technology recommendations. Journal of Management Information Systems, 25(1): 105-130.

Rendell, L., Fogarty, L., \& Laland, K. N. 2011. Runaway cultural niche construction. Philosophical Transactions of the Royal Society B: Biological Sciences, 366: 823-835.

Richerson, P. J., \& Boyd, R. 2000. The Pleistocene climate variation and the origin of human culture: Built for speed. In F. Tonneau \& N. S. Thompson (Eds.), Evolution, culture, and behavior: 1-45. New York: Kluwer Academic/Plenum.

Richerson, P. J., Boyd, R., \& Bettinger, R. 2001. Was agriculture impossible during the Pleistocene but mandatory during the Holocene? American Antiquity, 66: 387-411.

Richerson, P. J., Boyd, R., \& Henrich, J. 2003. Cultural evolution of human cooperation. In P. Hammerstein (Ed.), Genetic and cultural evolution of cooperation: 357-388. Cambridge, MA: MIT Press.

Rivkin, J. W., \& Siggelkow, N. 2003. Balancing search and stability: Interdependencies among elements of organizational design. Management Science, 49: 290-311.

Rowley-Conwy, P., \& Layton, R. 2011. Foraging and farming as niche construction: Stable and unstable adaptations. Philosophical Transactions of the Royal Society B: Biological Sciences, 366: 849-862.

Schein, E. H. 1985. Organizational culture and leadership. San Francisco: Jossey-Bass.

Service, E. R. 1975. Origins of the state and civilization: The process of cultural evolution. New York: Norton.

Sober, E., \& Wilson, D. S. 1998. Unto others: The evolution and psychology of unselfish behavior. Cambridge, MA: Harvard University Press.

Spisak, B. R., Nicholson, N., \& van Vugt, M. 2011. Leadership in organizations: An evolutionary perspective. In G. Saad (Ed.), Evolutionary psychology in the business sciences: 165-190. New York: Springer.

Suddaby, R., Hardy, C., \& Huy, Q. N. 2011. Introduction to special topic forum: Where are the new theories of organization? Academy of Management Review, 36: $236-$ 246.

Tennie, C., Call, J., \& Tomasello, M. 2009. Ratcheting up the ratchet: On the evolution of cumulative culture. Philosophical Transactions of the Royal Society B: Biological Sciences, 364: 2405-2415.

Trivers, R. L. 1971. The evolution of reciprocal altruism. Quarterly Review of Biology, 46: 35-57.

Uhl-Bien, M., Marion, R., \& McKelvey, B. 2007. Complexity leadership theory: Shifting leadership from the industrial age to the knowledge era. Leadership Quarterly, 18: $298-318$. 
Van Maanen, J., \& Schein, E. H. 1979. Towards a theory of organizational socialization. Research in Organizational Behavior, 1: 209-264.

van Vugt, M. 2006. Evolutionary origin of leadership and followership. Personality and Social Psychology Review, 10: 354-371.

van Vugt, M., Hogan, R., \& Kaiser, R. B. 2008. Leadership, followership, and evolution: Some lessons from the past. American Psychologist, 63: 182-196.

van Vugt, M., \& Spisak, B. R. 2008. Sex differences in the emergence of leadership during competitions within and between groups. Psychological Science, 19: 854-858.

Vaughn, K. J., Eerkens, J. W., \& Kantner, J. (Eds.). 2010. The evolution of leadership transitions in decision making from small-scale to middle-range societies. Santa Fe, NM: School for Advanced Research Press.

Vroom, V. H. 1964. Work and motivation. New York: Wiley.

Weaver, G. R., Treviño, L. K., \& Cochran, P. L. 1999. Integrated and decoupled corporate social performance: Manage- ment commitments, external pressures, and corporate ethics practices. Academy of Management Journal, 42: 539-552.

Weber, R., Camerer, C., Rottenstreich, Y., \& Knez, M. 2001. The illusion of leadership: Misattribution of cause in coordination games. Organization Science, 12: 582598.

Whetten, D. A. 1989. What constitutes a theoretical contribution? Academy of Management Review, 14: 490-495.

Williams, G. C. 1966. Adaptation and natural selection: $A$ critique of some current evolutionary thought. Princeton, NJ: Princeton University Press.

Wilson, D. S., van Vugt, M., \& O'Gorman, R. 2008. Multilevel selection theory and major evolutionary transitions: Implications for psychological science. Current Directions in Psychological Science, 17: 6-9.

Zahra, S. A., \& Pearce, J. A. 1990. Research evidence on the Miles-Snow typology. Journal of Management, 16: 751768.

Brian R. Spisak (b.r.spisak@vu.nl) is an assistant professor in the Department of Management and Organization at the VU University Amsterdam. He received his Ph.D. from the VU University Amsterdam. His research and applied work focuses on the evolution of leadership and how insights derived from this perspective can be used to influence processes such as innovation, intergroup conflict, and sustainability.

Michael J O'Brien (ObrienM@missouri.edu) is professor of anthropology and dean of the College of Arts and Science at the University of Missouri. He received his Ph.D. from the University of Texas at Austin. His work involves applying evolutionary theory and method to the study of cultural phenomena.

Nigel Nicholson (nnicholson@london.edu) is professor of organizational behavior at London Business School. He received his Ph.D. from the University of Wales. Through his research, writing, and executive teaching he has sought to bring the ideas of evolutionary science to bear on the field of business and management, with particular reference to leadership, family business, risk in financial markets, and biography.

Mark van Vugt (m.van.vugt@vu.nl) is professor of evolutionary and organizational psychology at the VU University Amsterdam and research associate at the University of Oxford. He received his Ph.D. from the University of Maastricht. He studies leadership, group, and organizational processes from an evolutionary perspective and applies evolutionary thinking to understand problems related to sustainability, economics, management, and war and peace. 